\title{
PENGARUH CUSTOMER RELATIONSHIP MANAGEMENT (CRM) TERHADAP LOYALITAS PELANGGAN PADA MASKAPAI PENERBANGAN GARUDA INDONESIA MELALUI PROGRAM FREQUENT FLYER
}

\author{
Eva Dwi Sundari \\ Program Studi Magister Manajemen Universitas Tarumanagara \\ evasundarisoekotjo@gmail.com
}

\begin{abstract}
The aim of this study is to examine the effect of Customer Relationship Management (CRM) on customer loyalty on Garuda Indonesia airlines through frequent flyer programs. The study sample was taken from Garuda Indonesia passengers over the age of 18 years. Primary data was collected through convenience sampling. Regression analysis is used to test hypothese. There is the influence of Customer Relationship Management on Customer Loyalty on Garuda Indonesia airlines, there is a Frequent Flyer influence on customer loyalty on Garuda Indonesia airlines, there is a frequent flyer influence to moderate Customer Relationship Management to Garuda Indonesia Customer Loyalty, there is the effect of Customer Relationship Management, Frequent Flyer for Garuda Indonesia airlines. It is better if further research is conducted in the long term, so that Garuda Indonesia CRM can be explored more far. While Garuda Indonesia's services cover almost all of Indonesia and several other countries. The literature that discusses CRM is still not much so that the dimensions of dimension elaboration are still limited. Research findings reveal the need and importance of a company to continuously improve Customer Relationship Management. This study shows the need to emphasize the use of critical customer loyalty and to recognize the nature and importance of frequent flyer moderation effects. The value of this research is a combined and practical theory and finds four management implications and three practical implications.
\end{abstract}

\begin{abstract}
Abstrak : Tujuan penelitian ini untuk menguji Pengaruh Customer Relationship Management (CRM) terhadap loyalitas pelanggan pada maskapai penerbangan Garuda Indonesia melalui program frequent flyer. Sampel penelitian diambil dari penumpang Garuda Indonesia berumur lebih dari 18 tahun. Data primer dikumpulkan melalui convenience sampling. Analisis Regresi digunakan untuk menguji hipotesis. Terdapat pengaruh Customer Relationship Management terhadap Loyalitas Pelanggan pada maskapai penerbangan Garuda Indonesia, terdapat pengaruh Frequent Flyer terhadap loyalitas pelanggan pada maskapai penerbangan Garuda Indonesia, terdapat pengaruh frequent flyer memoderasi Customer Relationship Management terhadap Loyalits Pelanggan Garuda Indonesia, terdapat pengaruh Customer Relationship Management, Frequent Flyer terhadap maskapai penerbangan Garuda Indonesia. Ada baiknya jika penelitian selanjutnya dilakukan dalam jangka panjang, sehingga CRM Garuda Indonesia bisa ditelaah lebih jauh. Literatur-literatur yang membahas CRM masih belum banyak sehingga pembuatan elaborasi dimensi-dimensinya masih terbatas. Temuan penelitian mengungkapkan perlunya dan pentingnya suatu perusahaan untuk meningkatkan Customer Relationship Management secara terus-menerus. Studi ini menunjukkan perlunya menekankan penggunaan loyalitas pelanggan yang kritis dan untuk menyadari sifat dan pentingnya efek moderasi dari frequent flyer. Nilai dari penelitian ini adalah teori gabungan dan praktis dan menemukan empat implikasi manajemen dan tiga implikasi praktis.
\end{abstract}

Keywords : Customer Relationship Management, Loyalitas Pelanggan, Frequent Flyer

\section{Pendahuluan}

Penelitian ini ditujukan langsung kepada pelanggan jasa penerbangan Garuda Indonesia kususnya bagi anggota GFF. Fokus penelitian ini ada pada bagaimana CRM yang diterapkan 
Garuda Indonesia dapat mempengaruhi loyalitas pelanggannya dengan moderasi efek loyalty program yaitu frequent flyer.

Pertumbuhan penumpang yang diukur dengan RPK (Revenue Passangers Kilometers), secara historis telah menunjukan pertumbuhan yang pesat. Penumpang internasional naik dengan CAGR (Compound annual growth rate) sebesar 4,6\% dri tahun 1985 sampai dengan tahun 2009. Selama periode tersebut jumlah penumpang di Asia Pasifik tercatat tumbuh pada tingkat tertinggi di dunia dan diperkirakan akan terus naiksecara signifikan di tahun-tahun mendatang. Volume penumpang di Asia Pasifik berjumlah sangat besar dan Asia Pasifik membukukan volume penumpang sekitar 27\% dari penerbangan dunia pada tahun 2009 . Penumpang yang berpergian diwilayah Asia Pasifik diperkirakan naik dengan pertumbuhan rata-rata majemuk pertahun sebesar 7,1\% dari tahun 2009 sampai dengan tahun 2009 dan penumpang yang pergi dan datang diwilayah aia Pasifik diperkirakan tumbuh pada tingkat CAGR 6,8\% dalam periode yang sama (The Boeing Company Current Market Outlook, 2003, 2009 \& 2010).

Loyalitas dapat dipahami sebagai sebuah konsep yang menekankan pada runtutan pembelian, seperti yang dikutip oleh Dick dan Basu (1994) dari Jacoby dan Olson (1970). Loyalitas pelanggan akan berpengaruh terhadap kelangsungan hidup perusahaan dimana perusahaan bertahan karena produk atau jasa yang digunakan terus-menerus oleh pelanggan. Loyalitas pelanggan berawal dari pelayanan perusahaan yang memuaskan sehingga menghasilkan kepuasan. Kepuasan pelanggan adalah membandingkan anatara kinerja yang dirasakan dengan yang diharapkan (kotler,2007). Kinerja pelayanan yang sesuai dengan harapan pelanggan akan berdampak pada kepuasan pelanggan dan memunculkan retained customer sehingga retained customer ini terus menggunkan produk yang sama dan membentuk loyalitas.

CRM merupakan suatu sistem yang dilaksanakan perusahaan dengan orientasi meningkatkan kualitas layanan dan menjaga hubungannya dengan pelanggan. Implementasi CRM memungkinkan adanya kepuasan pelanggan karena berusaha memantapkan, memelihara, dan memperkuat hubungan antara organisasi dengan pelanggan, dengan memandang pelanggan sebagai partner (Darsono,2008). Kepuasan pelanggan kini bergantung kepada penerapan CRM yang diterapkan oleh perusahaan. CRM membantu perusahaan mempelajari pelanggannya menolong perusahaan untuk mengenali profil pelanggan dan bisa mendapat pengertian yang lebih mendalam dari pelanggan tentang hal apa yang menguntungkan atau tidak menguntungkan sehingga perusahaan bisa melihat perkembangan tiap pelanggan (melalui frekuensi pemakaian jasa perusahaan) dan menerapkan program promosi perusahaan untuk mempertahankan pelanggan. CRM berperan menjaga kepuasan pelanggan agar pelanggan bertahan dengan produk atau jasa yang digunakannya sehingga menciptakan loyalitas pelanggan. Pemeliharaan hubungan yang baik kepada pelanggan melalui pemahaman kekurangan-kekurangan perusahaan dan perbaikan pelayanan berdasarkan pengimplementasian CRM yang baik akan meningkatkan loyalitas pelanggannya.

Dalam rangka mengimplementasikan CRM dalam industri penerbangan banyak maskapai membuat program kesetiaan yang disebut dengan Frequent Flyer Program (FFP). FFP merupakan sebuah program kesetiaan yang ditawarkan dengan cara mendaftarkan pelanggan yang memakai jasa pnerbangan dalam bentuk akumulasi poin yang dihubungkan dengan jarak tempuh penerbangan pada pesawat. Pertambahan poin (Frequent Flyer Miles) dapat ditukarkan untuk perjalanan udara gratis pembelian merchandise, atau untuk menambah keuntungan seperti prioritas booking atau akses kursi dibandara. Setiap maskapai penerbangan menawarkan jenis keuntungan FFP yang berbeda-beda.

Tujuan pada penelitian ini adalah :

1. Untuk mengetahui pengaruh Customer Relationship Management terhadap loyalitas pelanggan Garuda Indonesia 
2. Untuk untuk menguji apakah program Frequent Flyer dapat memoderasi antara pengaruh Customer Relationship Management terhadap loyalitas pelanggan Garuda Indonesia.

\section{Latar Belakang}

Pelanggan (customer) berbeda dengan konsumen (consumer), dimana seseorang dikatakan sebagai pelanggan apabila orang tersebut mulai membiasakan diri untuk membeli produk atau jasa yang ditawarkan oleh suatu badan usaha. Kebiasaan tersebut dapat dibangun melalui pembelian berulang-ulang dalam jangka waktu tertentu. Apabila dalam jangka waktu tertentu tidak melakukan pembelian ulang maka orang tersebut tidak dapat dikatakan sebagai pelanggan tetapi seorang pembeli atau konsumen (Musanto, 2004).

Kotler (2005) memberikan definisi yang serupa mengenai loyalitas pelanggan, yaitu suatu pembelian ulang yang dilakukan oleh seorang pelanggan karena komitmen pada suatu merk atau perusahaan. Menurutnya ada dua faktor yang mempengaruhi pelanggan untuk loyal, yaitu faktor harga yang yang membuat pelanggan memilih produk yang murah di antara pilihan yang ada, serta faktor kebiasaan dimana seseorang yang telah terbiasa menggunakan suatu merk akan sulit untuk berpindah ke merk lain.

Loyalitas pelanggan secara umum dapat diartikan sebagai kesetiaan seseorang atas suatu produk, baik barang maupun jasa tertentu. Loyalitas pelanggan merupakan manifestasi dan kelanjutan dari kepuasan pelanggan dalam menggunakan fasilitas maupun jasa pelayanan yang diberikan oleh perusahaan, serta untuk tetap menjadi pelanggan dari perusahaan tersebut. Hal ini menunjukkan bagaimana loyalitas itu dapat menjadi kenyataan, yaitu pertama sebagai loyalitas kognitif, kemudian loyalitas afektif, loyalitas konatif, dan akhirnya sebagai loyalitas tindakan.

CRM merupakan serangkaian aktivitas yang terintegrasi dalam rangka mempertahankan dan mengembangkan pelanggan yang menguntungkan sebagai bentuk tanggung jawab perusahaan terhadap pelanggan dalam mewujudkan kepuasan pelanggan. Kotler (2003) menyatakan bahwa CRM mendukung suatu perusahaan untuk menyediakan pelayanan kepada pelanggan secara real time dan menjalin hubungan dengan tiap pelanggan melalui penggunaan informasi mengenai pelanggan. Perusahaan dapat mengetahui gambaran akan keinginan dan kebutuhan pelanggan sehingga dapat menyesuaikan strategi dalam rangka pemenuhan keinginan dan kebutuhan pelanggan dengan baik.

Pengukuran selanjutnya dikemukakan oleh Kincaid (dikutip dari Francis Buttle, 2004) melalui bukunya yang berjudul Customer Relationship Management: Getting It Right melakukan pengembangan dimensi CRM dari Lukas. Menurutnya data dan informasi juga merupakan unsur penting pelaksanaan CRM, karena aktivitas CRM selalu dan akan selalu menggunakan data dan informasi, baik dari sisi perusahaan maupun pelanggan. Oleh sebab itu, data dan informasi masuk ke dalam dimensi CRM yang telah dikembangkan oleh Kincaid, sehingga pengembangan dimensi CRM dapat dijelaskan antara lain Data dan Informasi, Proses, Teknologi, Sumber Daya Manusia.

Program GFF Garuda Indonesia terbagi menjadi empat, yaitu GFF Regular, GFF Junior, Executive Card Plus (EC Plus) dan Garuda Indonesia Co-Brand dimana masing-masing program memiliki syarat dan metode penggunaan yang berbeda. GFF Regular diperuntukkan bagi anggota yang berumur 12 tahun ke atas. GFF Junior diperuntukkan bagi anggota di bawah umur12 tahun. EC Plus menyedikan layanan yang sama dengan GFF Gold, namun disertai dengan pertanggungan asuransi. Sedangkan GIC merupakan kombinasi GFF membercard dengan kartu kredit Citibank. Cara melakukan registrasi GFF membercard dapat dilakukan dengan mengisi formulir aplikasi yang tersedia di kantor penjualan domestik dan internasional Garuda Indonesia, counter pelayanan GFF Membership yang terletak di Bandara SoekarnoHatta Jakarta, dan Garuda Inflight Magazine. Selain itu registrasi juga dapat dilakukan secara online melalui situs GFF. 
GFF Regular terdiri dari empat kategori, yaitu Blue, Silver, Gold, dan Platinum bergantung pada frekuensi pemakaian. Saat awal penggunaan GFF Reguler, tiap anggota akan diberi Blue GFF membercard. Untuk tiap perjalanan udara yang dilakukan, anggota akan mendapatkan pertambahan poin yang dihitung dengan mileage (jarak tempuh). Semakin jauh jarak perjalanan yang ditempuh maka pertambahan poin yang didapat akan semakin besar. Setelahnya anggota dapat menukarkan pertambahan poin yang didapat dengan award ticket atau upgrade award. Dengan award ticket, anggota GFF dapat menukarkannya untuk perjalanan udara gratis atau merchandise yang dijual dalam katalog Garuda Indonesia.

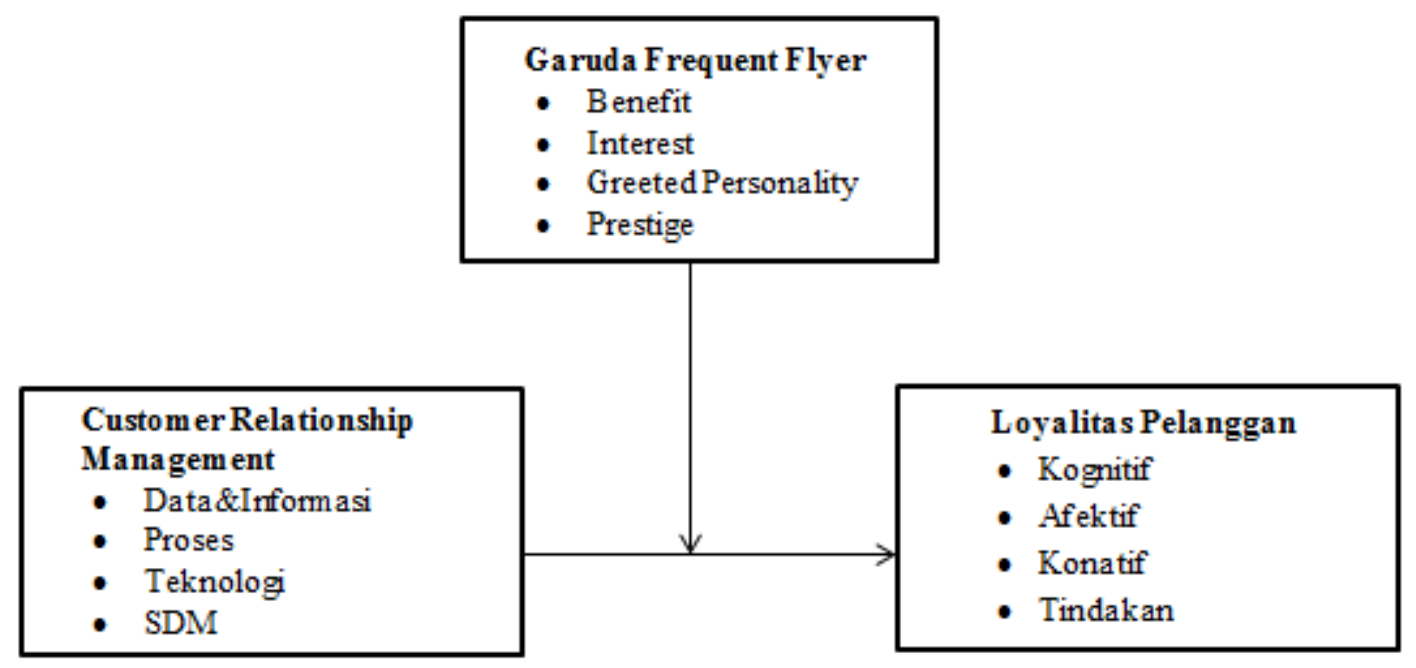

Hipotesis merupakan posisi yang akan diuji keberlakuannya atau merupakan suatu jawaban sementara atas pertanyaan penelitian (Prasetyo dan Jannah, 2005). Penggunaan hipotesis dalam sebuah penelitian bertujuan untuk membuktikan pernyataan atau proposisi mengenai sebuah faktor atau fenomena yang menjadi perhatian peneliti. Penelitian ini terdiri dari tiga variabel yang akan diteliti, yaitu CRM GFF dan loyalitas pelanggan. Rumusan hipotesis:

H1: Terdapat pengaruh antara Customer Relationship Management terhadap loyalitas pelanggan

H2: Terdapat pengaruh program Frequent Flyer memoderasi antara Customer Relationship Management terhadap loyalitas pelanggan

\section{Metode Penelitian}

Penelitian ini menggunakan pendekatan kuantitatif yang menggunakan cara berpikir deduktif dengan teori ditempatkan sebagai titik tolak utama untuk menjawab permasalahan yang diangkat dan proses penelitian dilakukan secara bertahap mengikuti satu garis lurus/linear. Untuk mendapatkan data dan informasi yang dibutuhkan dalam penelitian ini digunakan beberapa tekhnik pengumpulan data yang digunakan penelitian ini, adalah kuisioner, studi pustaka, dokumentasi, riset internet.

Operasional Penelitian Variabel Customer Relatioship Management (CRM) indikator dimensi meliputi Data dan Informasi, Proses, Tekhnologi, Sumber Daya Manusia, Variabel Garuda Frequent Flyer indikator dimensi meliputi Benefit, Interest, Greeted personality, Prestige, Variabel Loyalitas Pelanggan indikator dimensi meliputi Kognitif, Afektif, Konatif, Tindakan.

Berdasarkan penelitian yang telah dilakukan, maka diterima data responden sebanyak 163 orang dan di eliminasi sebanyak 25 responden sebesar 15,5\%, sedangkan yang bisa diolah memenuhi pernah menjadi penumpang maskapai penerbangan Garuda Indonesia sebanyak 138 responden atau $84,5 \%$ (data terlampir). Setelah dilakukan summary hasil kuisioner berikut 
perolehan data responden yang disajikan melalui tabel. Data primer dikumpulkan melalui convenience sampling. Analisis Regresi SPSS digunakan untuk menguji hipotesis.

Tabel I Hasil Uji Reliabilitas

\begin{tabular}{|l|l|}
\hline \multicolumn{1}{|c|}{ Variabel } & \multicolumn{1}{c|}{ Cronbach's-Alpha } \\
\hline CRM & 0,867 \\
\hline GFF & 0,912 \\
\hline Loyalitas & 0,922 \\
\hline
\end{tabular}

Tabel II Hasil Uji Multikolinearitas

\begin{tabular}{|l|l|l|l|}
\hline No. & \multicolumn{1}{|c|}{ Variabel } & VIF & \multicolumn{1}{c|}{ Keterangan } \\
\hline 1. & $\begin{array}{l}\text { Customer Relationship } \\
\text { Management }\end{array}$ & 2,825 & Tidak terdapat Multikolinearitas \\
\hline 2. & Garuda Frequent Flyer & 2,825 & Tidak terdapat Multikolinearitas \\
\hline
\end{tabular}

Tabel III Hasil Uji Normalitas

\begin{tabular}{|l|c|}
\hline \multicolumn{1}{|c|}{ Variabel } & Significant \\
\hline Customer Relationship Management & 0,646 \\
\hline Garuda Frequent Flyer & 0,018 \\
\hline Loyalitas & 0,358 \\
\hline
\end{tabular}

Tabel V Hasil Uji t Regresi Berganda

\begin{tabular}{|c|c|c|c|c|c|}
\hline \multirow{2}{*}{ Model } & \multicolumn{2}{|c|}{$\begin{array}{c}\text { Unstandardized } \\
\text { Coefficients }\end{array}$} & $\begin{array}{c}\text { Standardized } \\
\text { Coefficients }\end{array}$ & \multirow{2}{*}{$\mathbf{t}$} & \multirow{2}{*}{ Sig. } \\
\cline { 2 - 4 } & B & Std.Error & Beta & & \\
\hline $\mathbf{1}$ (Constant) & 2,415 & 1,356 & & 1,782 & 0,082 \\
\hline CRM & 0,193 & 0,082 & 0,335 & 2,372 & 0,022 \\
\hline GFF & 0,502 & 0,134 & 0,531 & 3,758 & 0,000 \\
\hline
\end{tabular}


Tabel VI Hasil Uji F Regresi Berganda

\begin{tabular}{|l|l|l|l|l|l|l|}
\hline \multicolumn{2}{|c|}{ Model } & $\begin{array}{c}\text { Sum Of } \\
\text { Squares }\end{array}$ & df & $\begin{array}{c}\text { Mean } \\
\text { Square }\end{array}$ & F & Sig \\
\hline 1 & Regresion & 487,433 & 2 & 243,716 & 48,127 & $0,000 \mathrm{~b}$ \\
\hline & Residual & 227,880 & 45 & 5,064 & & \\
\hline & Total & 715,313 & 47 & & & \\
\hline
\end{tabular}

Tabel VIII Hasil Uji Analisis Moderator Kedua

\begin{tabular}{|l|c|c|c|c|c|}
\hline \multirow{2}{*}{ Model } & \multicolumn{2}{|c|}{$\begin{array}{c}\text { Unstandardized } \\
\text { coefficients }\end{array}$} & $\begin{array}{c}\text { Standardized } \\
\text { Coefficients }\end{array}$ & \multirow{2}{*}{ t } & \multirow{2}{*}{ Sig. } \\
\cline { 2 - 4 } & B & Std.Error & Beta & & \\
\hline Constant & $-5,023$ & 2,846 & & $-1,765$ & 0,085 \\
\hline CRM & 0,540 & 0,141 & 0,937 & 3,831 & 0,000 \\
\hline GFF & 1,067 & 0,230 & 1,130 & 4,637 & 0,000 \\
\hline CRMGFF & $-0,025$ & 0,008 & $-1,162$ & $-2,912$ & 0,006 \\
\hline R Square & \multicolumn{7}{|l}{0,733} \\
\hline
\end{tabular}

\section{Kesimpulan}

1. Terdapat pengaruh Customer Relationship Management terhadap Loyalitas Pelanggan pada maskapai penerbangan Garuda Indonesia

2. Terdapat pengaruh Frequent Flyer terhadap loyalitas pelanggan pada maskapai penerbangan Garuda Indonesia

3. Terdapat pengaruh frequent flyer memoderasi Customer Relationship Management terhadap Loyalits Pelanggan Garuda Indonesia

4. Terdapat pengaruh Customer RelationshipManagement, Frequent Flyer terhadap maskapai penerbangan Garuda Indonesia

\section{Reference :}

Kotler, Philip \& Kevin Keller. 2006. Framework for Marketing Management \& Custom Case. 3rd Edition. New Jersey: Prentice Hall. 